\title{
Analisis Citra Sinar-X Tulang Tangan Menggunakan Metode Thresholding Otsu Untuk Identifikasi Osteoporosis
}

Wara Mitha Nabella1) ${ }^{1)}$, Joko Sampurno ${ }^{1)}$, Nurhasanah ${ }^{11}$

1) Jurusan Fisika FMIPA Universitas Tanjungpura Pontianak

Email :warapotter@yahoo.co.id

\begin{abstract}
Abstrak
Penelitian ini menentukan nilai thresholding pada citra tulang tangan normal dan osteoporosis. Citra yang digunakan adalah 5 citra tulang tangan normal dan 3 citra tulang tangan osteoporosis. Penentuan nilai thresholding di sini menggunakan metode Otsu. Hasil penelitian menunjukkan nilai thresholding tertinggi pada citra tulang tangan normal adalah 0,1765 dan nilai thresholding terendah adalah 0,1020. Sedangkan pada citra tulang tangan osteoporosis didapat nilai thresholding tertinggi adalah 0,0627 dan nilai thresholding terendah adalah 0,0431. Nilai thresholding yang tinggi menunjukkan tulang tangan normal dan nilai thresholding yang rendah menunjukkan tulang tangan osteoporosis. Nilai thresholding yang dihasilkan dianggap sebagai nilai densitas pada citra tulang tersebut. Dengan demikian, analisa citra tulang tangan dengan metode thresholding Otsu dapat dijadikan metode baru untuk identifikasi osteoporosis.
\end{abstract}

Kata Kunci: osteoporosis, thresholding, metode Otsu

\section{Pendahuluan}

Rangka tubuh manusia adalah rangkaian tulang-tulang yang tersusun secara teratur dan berfungsi sebagai tempat melekatnya otot dan pelindung organ lunak. Tulang selalu tumbuh dan berkembang seiring bertambahnya usia, sehingga kecenderungan tingkat terkena osteoporosis juga semakin tinggi jika disertai pola hidup yang tidak sehat dan kurangnya asupan kalsium dan fosfor (Gomez, 2006).

Ada beberapa penelitian yang telah dilakukan dengan memanfaatkan citra sinar-X hasil pemeriksaan radiologi untuk diagnosa dini osteoporosis. Penelitian yang telah dilakukan Mulyono (2008) menyebutkan bahwa dengan analisa tekstur dari gabungan citra sinar- $\mathrm{X}$ tulang tangan, tulang lutut, dan tulang rahang dapat digunakan untuk mendeteksi osteoporosis. Hasil pemeriksaan radiologi yang berupa foto citra sinar-X dapat digunakan beberapa metode, salah satu diantaranya adalah metode Otsu sebagaimana yang telah dilakukan oleh Cahyaningsih (2010).

Berdasarkan permasalahan di atas terkait mengenai pendeteksian penyakit osteoporosis maka penelitian ini akan menggunakan citra tulang tangan yang cenderung lebih mudah diambil. Citra tersebut diolah sehingga diperoleh nilai thresholding yang merupakan pembeda antara tulang tangan normal dan osteoporosis

Hasil penelitian ini diharapkan dapat bermanfaat dalam identifikasi tulang osteoporosis.

\section{Landasan Teori}

\subsection{Computed Tomography (CT)}

Computed Tomography (CT) merupakan alat diagnosa sinar-X yang lebih canggih dengan metode tomografi modern untuk menginterpretasikan sinar-X yang menghasilkan gambar irisan melintang dengan hasil tampilan dalam skala algoritma. Hasil pemeriksaan radiologi CT menghasilkan gambaran potong lintang dari semua jaringan tubuh, gambaran tulang, jaringan lunak (Gabriel, 1996).

Proses CT menghasilkan suatu citra yang merupakan hasil representasi (gambaran), kemiripan dari suatu objek. Citra dapat didefenisikan sebagai fungsi $f(x, y)$ dimana $x$ dan $\mathrm{y}$ adalah koordinat ruang dan $\mathrm{f}$ disebut sebagai intensitas atau gray level dari sebuah citra pada titik yang terletak pada koordinat $\mathrm{x}$ dan $\mathrm{y}$. Citra yang dihasilkan dari proses CT perlu diolah kembali agar menghasilkan kualitas citra yang lebih baik. Proses peningkatan atau perbaikan kualitas citra tersebut diantaranya adalah perbaikan citra warna yang kurang tajam, kabur dan mengandung bintik-bintik putih (Ahmad, 2005).

\subsection{Pre-processing}

Pre-processing merupakan proses yang digunakan untuk meningkatkan kualitas tampilan citra agar memiliki format yang lebih baik sehingga citra tersebut menjadi lebih mudah diolah lebih lanjut. Perbaikan kualitas citra (image enhancement) adalah proses memperjelas dan mempertajam fitur tertentu dari citra agar citra lebih mudah dianalisis (Munir, 2004). 


\subsection{Segmentasi}

Proses segmentasi membagi citra menjadi bagian yang diharapkan ke dalam daerah intensitasnya masing-masing sehingga bisa membedakan antara objek dan latar belakangnya. Dengan demikian, citra terbagi atas dua bagian, yaitu bagian hitam dan bagian putih atau warna-warna yang membatasi setiap wilayah (Munir, 2004).

\subsection{Thresholding}

Thresholding digunakan untuk mengatur jumlah derajat keabuan yang ada pada citra. Thresholding adalah suatu proses yang digunakan untuk menghasilkan citra biner yaitu citra yang memiliki dua nilai tingkat keabuan yaitu hitam dan putih bergantung apakah piksel asli tersebut lebih besar atau lebih kecil dari nilai ambang batas (T). Piksel akan diubah menjadi putih jika nilai tingkat keabuannya lebih besar dari nilai $\mathrm{T}$ dan akan diubah menjadi hitam jika nilai tingkat keabuannya lebih kecil atau sama dengan $\mathrm{T}$.

Secara umum, proses binerisasi citra gray scale untuk menghasilkan citra biner adalah (Sigit, 2005) :

$$
g(\mathrm{x}, \mathrm{y})=\left\{\begin{array}{l}
1 \text { if } f(x, y)>T \\
0 \text { if } f(x, y) \leq T
\end{array}\right\}
$$

\subsection{Metode Otsu}

Metode Otsu merupakan metode dalam segmentasi citra yang menghitung nilai ambang $\mathrm{T}$ secara otomatis berdasarkan citra masukan. Pendekatan yang digunakan oleh metode Otsu adalah dengan analisis diskriminan yaitu menentukan suatu variabel yang dapat membedakan antara dua atau lebih kelompok yang muncul secara alami. Analisis diskriminan akan memaksimumkan variabel tersebut agar dapat membagi objek latar depan dan latar belakang. Tujuan dari metode Otsu adalah membagi histogram citra gray level ke dalam dua daerah yang berbeda secara otomatis tanpa membutuhkan bantuan user untuk memasukkan nilai ambang (Cahyaningsih, 2010). Beberapa penelitian yang telah dilakukan dengan metode Otsu diantaranya Identifikasi Bakteri Tuberkulosis Secara Otomatis (Mirnasari dan Adi, 2013) dan Segmentasi Citra Medis Menggunakan Metode Otsu dan Metode Iterasi (Ferry, 2013). Formulasi dari metode Otsu adalah nilai ambang yang akan dicari dari suatu citra gray level dinyatakan dengan $\mathrm{k}$. Nilai $\mathrm{k}$ berkisar antara 1 sampai $\mathrm{L}$, dengan nilai $\mathrm{L}=255$. Probabilitas untuk piksel i dinyatakan dengan (Gonzales dan Woods, 2002) :

$$
\mathrm{P}_{\mathrm{i}}=\frac{n_{i}}{N}
$$

dengan: $\mathrm{P}_{\mathrm{i}}=$ probabilitas piksel ke-i

$n_{i}=$ menyatakan jumlah piksel dengan nilai tingkat keabuan i

$N=$ menyatakan total jumlah piksel pada gambar

Nilai momen kumulatif ke-nol (3), nilai momen kumulatif ke-satu (4) dan nilai rata-rata (5) berturut-turut adalah(Gonzales dan Woods, 2002) :

$$
\begin{aligned}
\omega(\mathrm{k}) & =\sum_{i=1}^{k} P i \\
\mu(\mathrm{k}) & =\sum_{i=1}^{k} i . P i \\
(4) & \\
\mu_{\mathrm{T}} & =\sum_{i=1}^{L} i . P i
\end{aligned}
$$

dimana : $\omega(\mathrm{k})=$ momen kumulatif ke-nol

$$
\begin{aligned}
& \mu(\mathrm{k})=\text { momen kumulatif ke-satu } \\
& \mu_{\mathrm{T}} \quad=\text { nilai rata-rata }
\end{aligned}
$$

nilai ambang $\mathrm{k}$ dapat ditentukan dengan memaksimumkan persamaan (Gonzales dan Woods, 2002) :

$$
\sigma_{B}^{2}\left(\mathrm{k}^{*}\right)=\max _{1 \leq \mathrm{k} \leq \mathrm{L}} \sigma_{B}^{2}(\mathrm{k})
$$

dengan $\sigma_{B}^{2}\left(\mathrm{k}^{*}\right)=\frac{\left\lfloor\mu_{T} \omega(k)-\mu(k)\right\rfloor}{\omega(k)[1-\omega(k)]}$

\subsection{Osteoporosis}

Tulang sebagai jaringan yang kuat dalam tubuh sehingga dapat menopang aktifitas tubuh. Salah satu gangguan pada tulang adalah osteoporosis. Osteoporosis adalah tulang yang keropos, yaitu penyakit dengan berkurangnya atau penurunan massa tulang disertai gangguan mikroarsitektur tulang dan penurunan kualitas jaringan tulang, yang dapat menimbulkan kerapuhan tulang (Thandra, 2009).

Osteoporosis umumnya terjadi ketika seseorang berumur lebih dari 45 tahun dan khususnya pada perempuan $(80 \%)$ dibandingkan dengan laki-laki (20\%). Secara umum dipercaya bahwa foto sinar-X dapat mendeteksi osteoporosis apabila defisit mineral tulangnya mencapai >30\% (Thandra, 2009).

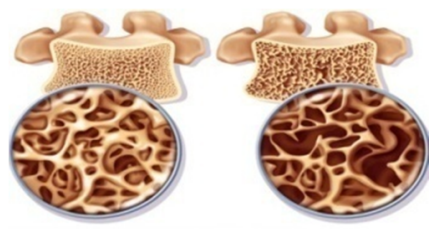

Gambar 1. Tulang normal dan tulang osteoporosis (Thandra, 2009). 


\section{Metodologi}

Sampel yang digunakan pada penelitian ini adalah hasil pemeriksaan radiologi berupa 5 citra sinar-X tulang tangan normal dan 3 citra sinar-X tulang tangan osteoporosis. Setelah itu pada citra dilakukan proses segmentasi yaitu proses Otsu. Proses Otsu bertujuan untuk mencari nilai threshold (ambang) yang tepat agar dapat memisahkan bagian manakah yang cenderung hitam dan bagian manakah cenderung putih. Berikut diagram alir dari penelitian ini :

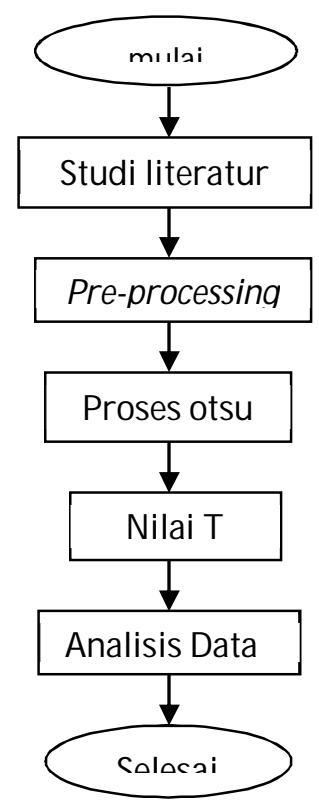

Gambar 2. Diagram Alir

\section{Hasil dan Diskusi}

Sampel yang digunakan dalam proses segmentasi adalah 5 citra sinar-X tulang tangan normal dan 3 tulang tangan osteoporosis. Citra asli tulang tangan dapat dilihat pada Gambar 3 :

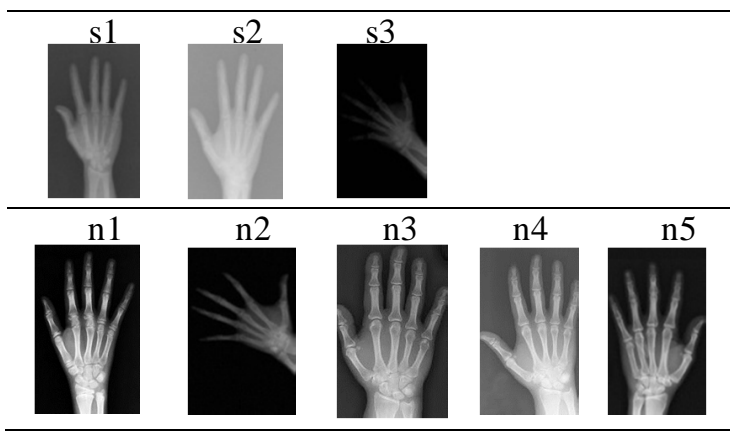

Gambar 3.Citra asli dengan S menunjukan tulang tangan Osteoporosis dan $\mathrm{N}$ menunjukan tulang tangan normal

Setelah citra asli diinput, proses selanjutnya yaitu proses segmentasi dengan metode thresholding Otsu. Dari proses ini, didapat nilai ambang. Nilai ambang pada citra tulang tangan osteoporosis sebagaimana dapat dilihat pada Gambar 4 :

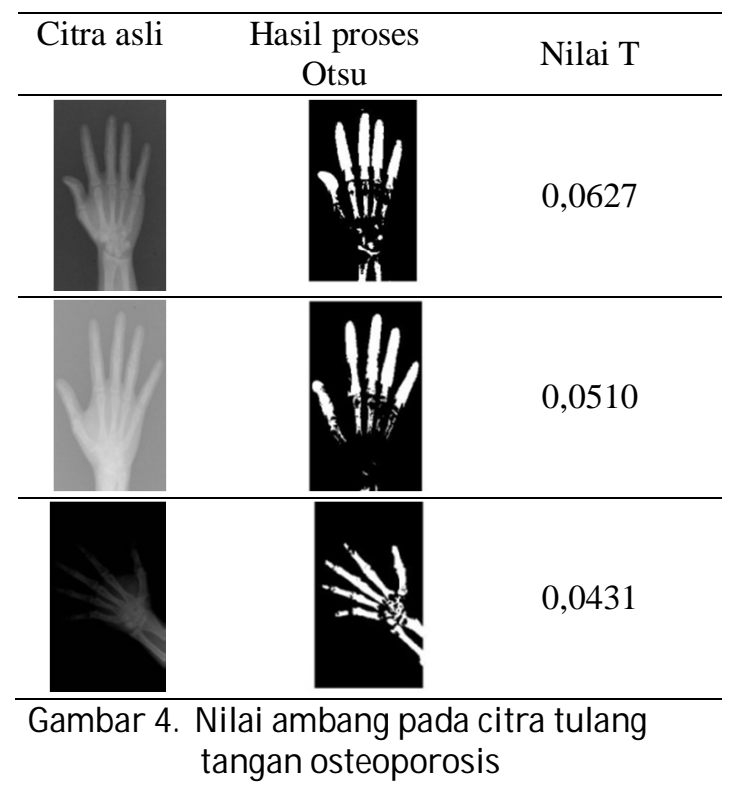

Sedangkan nilai ambang pada citra tulang tangan normal dapat dilihat sebagaimana ditunjukan pada Gambar 5:

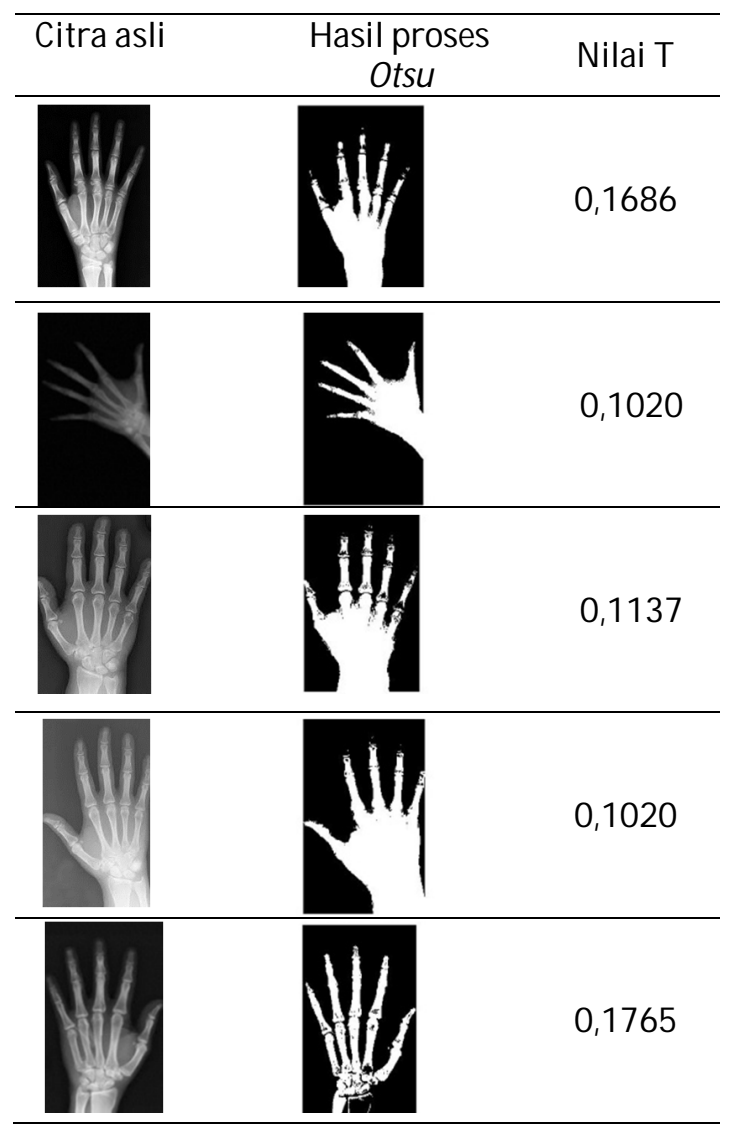

Gambar 5. Nilai ambang pada citra tulang tangan normal

Input citra merupakan citra asli yang disegmentasi dengan proses thresholding Otsu. Citra dengan 5 tulang tangan normal dan 3 
tulang tangan osteoporosis dibuat dalam ukuran piksel yang sama yaitu 160 x 272 dan dalam format jpg. Dari proses Otsu, pada citra tulang tangan normal didapat nilai ambang tertinggi yaitu dengan nilai 0,1765 dan nilai ambang terendah yaitu dengan nilai 0,1020 yang dapat dilihat pada Gambar 5. Sedangkan pada citra tulang tangan osteoporosis didapat nilai ambang tertinggi yaitu dengan nilai 0,0627 dan nilai ambang terendah yaitu dengan nilai 0,0431 yang dapat dilihat pada Gambar 4. Dari hasil yang didapat terlihat bahwa nilai ambang untuk tulang tangan osteoporosis adalah kecil. Nilai thresholding yang dihasilkan dianggap sebagai nilai densitas (kerapatan) dari citra tulang tangan tersebut.

\section{Kesimpulan}

Dari penelitian ini dapat dilihat nilai thresholding pada citra tulang tangan normal berkisar antara 0,1020 sampai 0,1765. Sedangkan nilai thresholding pada citra tulang tangan osteoporosis berkisar antara 0,0431 sampai 0,0627 . Dengan terkelompoknya nilai ambang (T) ini maka dapat disimpulkan bahwa analisis citra tulang tangan dengan metode thresholding Otsu dapat dijadikan sebagai metode baru untuk identifikasi osteoporosis.

\section{Daftar Pustaka}

Ahmad, Usman. 2005. Pengolahan Citra Digital dan Teknik Pemrogramannya. Yogyakarta : Graha Ilmu.

Cahyaningsih, Sri. 2010. Deteksi Osteoporosis Dengan Thresholding Metode Otsu Pada Citra X-ray Tulang Rahang. Jurusan Fisikan Fakultas Sains dan Teknologi UIN : Malang.

Ferry, Alvia Mandasari. 2013. Segmentasi Citra Medis menggunakan Metode Otsu dan Iterasi. Jurusan Teknik Informatika Fakultas Sains dan Teknologi UIN Sunan kalijaga : Yogyakarta.

Gabriel, J.F. 1996. Fisika Kedokteran. Penerbit Buku Kedokteran : EGC : Jakarta.

Gomez, Joan. 2006. Awas Pengeroposan Tulang : bagaimana menghindari dan Menghadapinya. Arcan : Jakarta.

Gonzalez, R.C., Woods, R.E. 2002. Digital Image Processing Second edition. Prentice Hall, New Jersey.

Mirnasari, Nelly dan Adi, kusworo. 2013. Aplikasi Metode Otsu Untuk Identifikasi Bakteri Tuberkulosis Secara Otomatis. Jurusan Fisika Universitas Dipenogoro :Semarang.
Mulyono, Agus. 2008. Analisis Tekstur Citra XRay Tulang Tangan, Tulang lutut dan Tulang Rahang Untuk Identifikasi Osteoporosis. Tesis Program Pascasarjana. Universitas Brawijaya : Malang.

Munir, Rinaldi. 2004. Pengolahan Citra Digital Dengan Pendekatan Algoritmik. Bandung : Informatika : Bandung.

Sigit, Riyanto dkk. 2005. Step By Step Pengolahan Citra Digital. Penerbit Andi : Yogyakarta

Thandra, Hans. 2009. Segala Sesuatu yang Harus Anda Ketahui Tentang Osteoporosis. Gramedia : Jakarta 